Research Article

\title{
Acute Encephalitis Syndrome in Muzaffarpur, Bihar; A Different Perspective
}

\author{
Anil Kumar', Deepika Karotia ${ }^{2}$ \\ ${ }^{1}$ Deputy Director General (Leprosy), National Leprosy Eradication Program, Directorate General of Health Services, Ministry \\ of Health \& Family Welfare. \\ ${ }^{2}$ National Consultant (Public Health), National Leprosy Eradication Program. \\ DOI: https://doi.org/10.24321/2455.7048.201912
}

\section{I $\quad \mathbf{N} \quad \mathbf{F} \quad \mathbf{O}$}

\section{Corresponding Author:}

Deepika Karotia, National Consultant (Public Health), National Leprosy Eradication Program.

E-mail Id:

ncph.cld@gmail.com

Orcid Id:

https://orcid.org/0000-0001-8657-4897

How to cite this article:

Kumar A, Karotia D. Acute Encephalitis Syndrome in Muzaffarpur, Bihar; A Different Perspective. Epidem Int 2019; 4(3): 4-9.

Date of Submission: 2019-08-17

Date of Acceptance: 2019-11-14

\section{$\begin{array}{lllllllllll}\mathbf{A} & \mathbf{B} & \mathbf{S} & \mathbf{T} & \mathbf{R} & \mathbf{A} & \mathbf{C} & \mathbf{T}\end{array}$}

Introduction: Acute Encephalitis Syndrome (AES) is a disease characterized by fever and mental confusion, disorientation, delirium, or coma. It could be due to various causes such as viruses, bacteria, fungus, parasites, spirochetes, chemical and toxins.

Objective: Epidemiological investigation of acute encephalitis syndrome occurred in Muzaffarpur, Bihar in 2011.

Methods: This epidemiological investigation was done by a team consisting of experts from various disciplines. The team visited Muzaffarpur, from $14^{\text {th }}$ to $20^{\text {th }}$ July 2011 and reviewed the situation of deaths among children due to AES, as directed by the Authorities.

Results: A total of 147 cases of fever with altered sensorium were admitted between $11^{\text {th }}$ June to $18^{\text {th }}$ July 2011 in a private hospital and a Medical College Hospital of Muzaffarpur. Out of these, 54 patients died indicating case fatality rate of $36.73 \%$. Evidences suggest that there were increased chances of contacts between cases and wild rats during the period of occurrence of outbreak. Etiological agent could not be identified by laboratory tests.

Conclusion: Clinico-epidemiological and environmental evidence supports the diagnosis of Acute Encephalitis Syndrome which has significant mortality, affecting predominantly rural population with poor sanitation and presence of wild rats.

Keywords: Acute Encephalitis Syndrome, Epidemic Investigation, Zoonosis, Lychee

\section{Introduction}

The disease, Acute Encephalitis Syndrome (AES) is characterized by acute onset of fever and neurological manifestation i.e., mental confusion, disorientation, delirium, or coma.

In India, AES have been mainly caused by the viruses. However during last few decades other sources are also being reported, which are bacteria, fungus, parasites, spirochetes, chemical and toxins. In addition to viral encephalitis it is caused by leptospirosis and toxoplasmosis (severe form). ${ }^{1}$

Due to its high morbidity and mortality, whenever such outbreak occurs there is a need to investigate the causes and measures should be instituted without delay for prevention and control of suffering and deaths. 


\section{Material and Methods}

\section{Study Setting}

Muzaffarpur district is situated in northern part of Bihar and is bounded by the districts of Sitamarhi \& East Champaran on its northern side, Darbhanga and Samastipur districts on eastern side, Vaishali \& Saran districts on southern side and district Saran \& Gopalganj on its western side. As per census 2001, district population was 37.4 lakh, out of which about 2.74 lakh (7.3\%) was urban. The population density of the district was 1,180 per Sq Km. and overall literacy rate was $48.15 \%$. At the time of investigation, the district had 1,811 Villages. In respect to infrastructure there were 16 block Primary Health Centres (PHC)s, 59 Additional Primary Health Centre (APHCs), 478 sub-centres, one district hospital and a medical college (Figure 1 ).

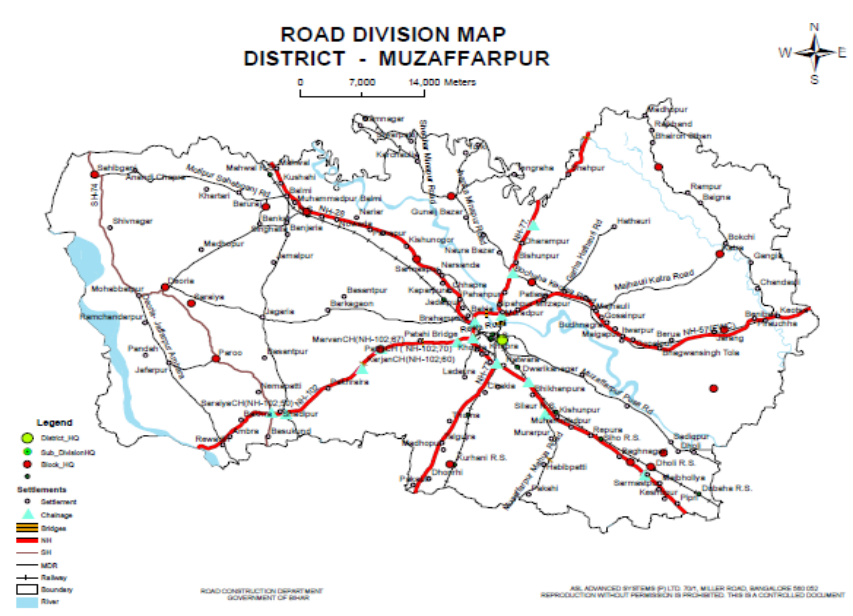

Figure I.Map of Muzaffarpur

The main crops are Wheat, Paddy, Pulses, Oil seeds, Lychee (Litchi chinensis) and Mango. During the outbreak period, most of the agriculture fields were barren and litchi fruits were being plucked. Houses are mostly mixed dwellings; human and cattle live together. The main occupation of the people in Muzaffarpur is agriculture, fisheries and daily wage labour.

\section{Methodology}

A multidisciplinary team headed by National Centre for Disease Control (NCDC) was constituted. The team had visited Muzaffarpur, from $14^{\text {th }}$ to $20^{\text {th }}$ July with objective to review the situation of deaths among children due to AES, as directed by the Authorities. Following activities were carried out:

- Desk review \& analysis of available data.

- 20 families each from the affected and unaffected villages were visited to collect the information on various variables.

- Discussions with clinicians, health and other authorities, community representatives and family members of cases.
- Collection of clinical specimens for laboratory investigations.

- Entomological investigations including mosquito collections.

The clinicians of the team clinically examined two cases admitted in SKMC hospital and interacted with various stakeholders: Dr. Gopal Sharma, S.K Medical College, Medical Superintendent, Dr. R.P Gupta, Pediatrician, S.K Medical College, Muzaffarpur and medical officer incharge, Mussari PHC. They also visited affected villages and interacted with cases and their families.

In addition to the survey and case control study in community the Team collected serum samples from 9 cases and 8 contacts, more than 300 mosquitoes, 3 serum samples from pigs.

Clinical samples collected from many patients, contacts and controls and one brain biopsy sample were sent to NIV, Pune.

\section{Observations}

\section{Morbidity and Mortality}

A total of 147 cases of fever with altered sensorium were admitted between $11^{\text {th }}$ June to $18^{\text {th }}$ July 2011 in the Krishnadevi Deviprasad Kejriwal Maternity Hospital (KDKMH), Muzaffarpur \& Shri Krishna Singh Medical College and Hospital (SKMCH), Muzaffarpur, as reported by the district authorities. Out of these, 54 patients died indicating case fatality rate of $36.73 \%$.

\section{Clinical Presentation of Cases}

- No significant prodrome was found documented in the records reviewed.

- Cases presented with acute onset of fever, convulsion followed by loss of consciousness.

- No documentation of respiratory, GIT or bleeding manifestation or accompanying rash was found recorded.

- Few children were brought in state of shock and were provided supportive treatment.

- Many of the children died within 24-48hours. It was communicated that these children could not be investigated because of their poor general conditions.

- Cerebrospinal Fluid (CSF) examination was not contributory. Similarly serum electrolytes were normal in majority of the cases.

- Information regarding non-contrast CT was available of 2 cases. Both the cases showed hypodensities suggesting cerebritis or encephalitis.

- Blood sugar reports were available of13 cases out of which 6 shown hypoglycemia (Blood sugar $\leq 50 \mathrm{mg} \%$ ).

- Kidney function tests were normal. Liver function test were not done. 


\section{Epidemiological Profile}

\section{Time Distribution}

A Peak in the number of cases was observed on $17^{\text {th }}$ June, 2011. There was also a second peak on 23rd June, 2011 (Figure 2). The day wise distribution of cases is as given below:

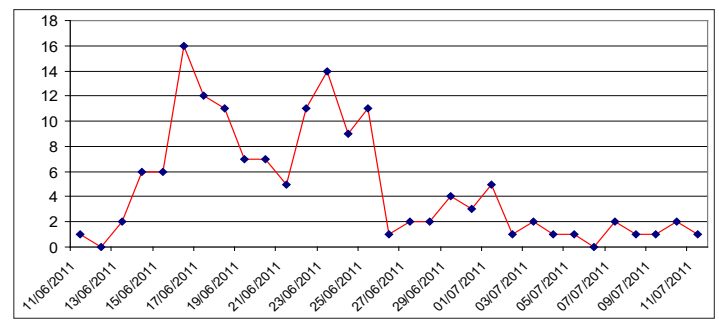

Figure 2.Day-wise distribution of cases

There have been reports of rain between two peaks. The day wise distribution of cases and rain incidence is as given below (Figure 3):

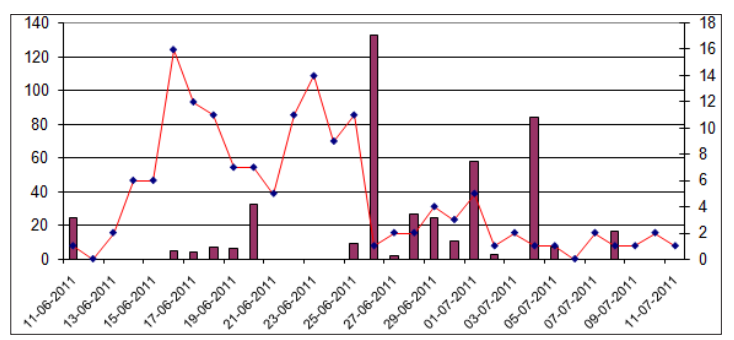

Figure 3.Day wise distribution of cases and rain incidence

\section{Place Distribution}

A total of 116 cases were reported from Muzaffarpur District as per detail given in Table 1 below.

Table I.Block-wise cases AES reported from Muzaffarpur district

\begin{tabular}{|c|c|c|}
\hline S.No. & Name of Block & Cases \\
\hline 1. & Minapur & 20 \\
\hline 2. & Kudhani & 2 \\
\hline 3. & Musahari & 48 \\
\hline 4. & Kanti & 17 \\
\hline 5. & Vochaha & 7 \\
\hline 6. & Katra & 3 \\
\hline 7. & Sakra & 7 \\
\hline 8. & Motipur & 5 \\
\hline 9. & Mauraui & 1 \\
\hline 10. & Paru & 3 \\
\hline 11 & Marwan & 2 \\
\hline 12. & Sahibganj & 3 \\
\hline & TOTAL & 116 \\
\hline
\end{tabular}

Majority of the cases were reported from four high litchi productivity blocks of Mushari, Bouchan, Minapur and Kantiand Marwan (Figure 4). These Blocks are located in Burhi Gandak riverbed where soil is loose and sandy, suitable for growth of litchi trees and also where wild rats can easily make burrows.

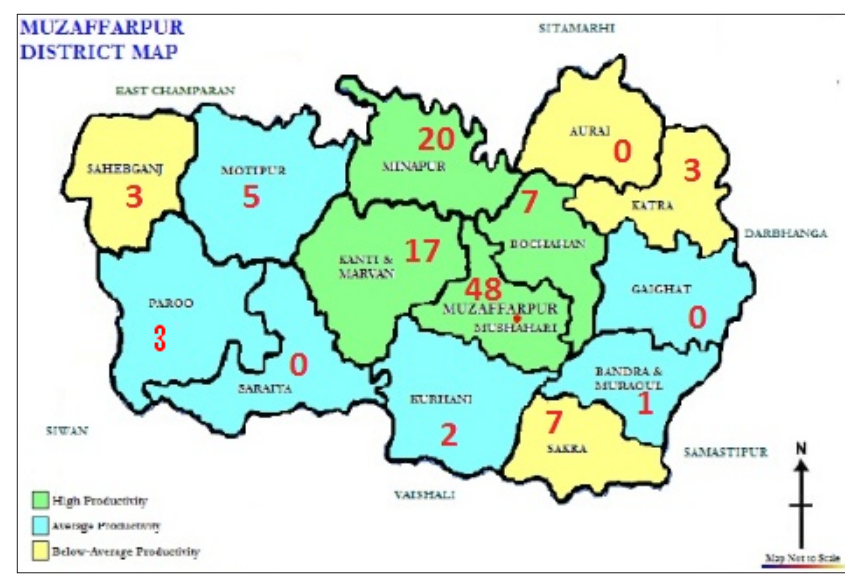

Figure 4.Map of Muzaffarpur showing block-wise distribution of cases and litchi productivity Source: EDA Rural Systems

\section{Person Distribution}

Majority of cases (92\%) were below the age of 8 yrs. It was also observed that no case was reported among adults (Figure 5).

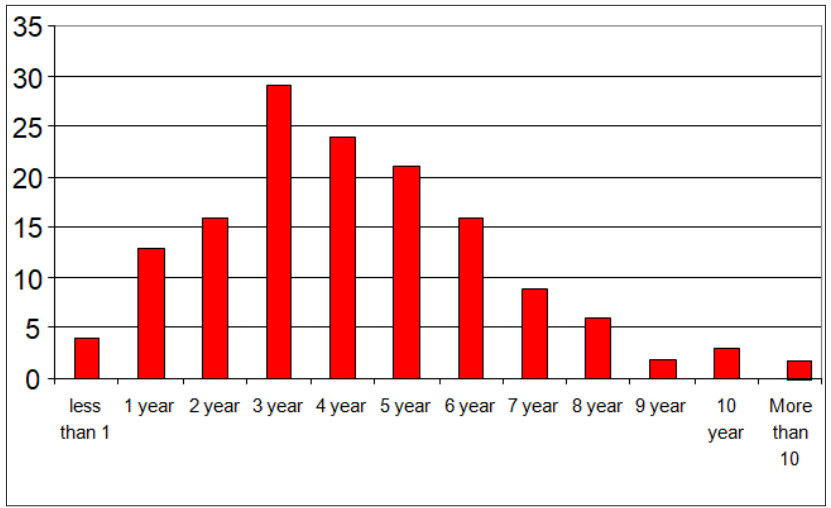

Figure 5.Distribution of the cases in respect to age In addition to the study and analysis of reported data the team conducted the following Epidemiological studies in community:

a. Comparison of epidemiological data from families of cases and controls

Epidemiological data was collected from the families of 13 cases and also from 13 controls (matching age and sex) from nearby village, from where no case was reported during last 5 or more years. No significant difference in terms of family occupation, caste, religion, family income, type of house, source of drinking water, presence of domestic animal in 
the house, use of insecticide/ rodenticide, abnormal death of animals in the locality was found.

\section{b. Community survey of affected and unaffected villages}

Survey was conducted, in 20 houses per village in 13 villages from where cases were reported and also in 13 villages from where cases were not reported during last 5 or more years, to collect information on involvement of the family in litchi cultivation, presence of domestic rodents in the house, presences of domestic animals, clothing habits of children. No significant difference could be found.

\section{Additional Important Epidemiological Observations}

- Majority of the houses (69.23\%), from where cases occurred, were either located outside the village or located at any extreme end of the villages (Figure $7 \& 8$ ).

- Majority of the houses (84.6\%), were surrounded by either farmland or litchi garden or any other type of agriculture land.

- Majority of cases (76.92\%) were having history of regular visits either to litchi garden, empty farmland or other areas where wild rats were found.

- Majority of the cases (76.92\%) (families visited by team) were vaccinated against Japanese Encephalitis.

- Majority of the cases (84.62\%) (families visited by team) reported symptoms of the disease during early hours of the day i.e. 4.00 AM to 8.00 AM.

- Majority of the cases (76.92\%) (families visited by team) did not give history of eating litchi during last one week prior to onset of illness. There was no report of secondary cases in the family, neighborhood and among health care workers despite close proximity with the suspected cases.

- The nutritional status of children who developed encephalitis was poor but their unaffected siblings were also poorly nourished.

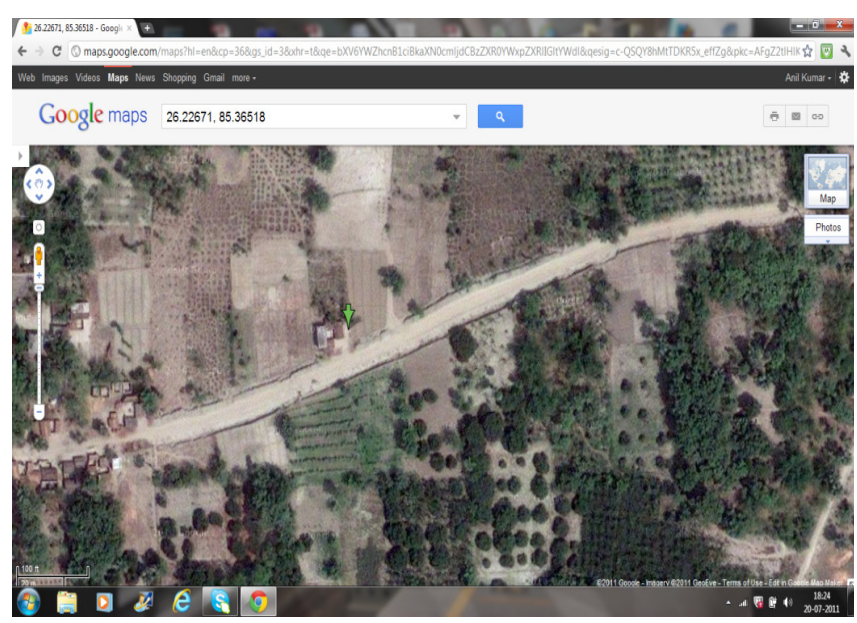

Figure 6.Google map showing location of house of the case outside main village
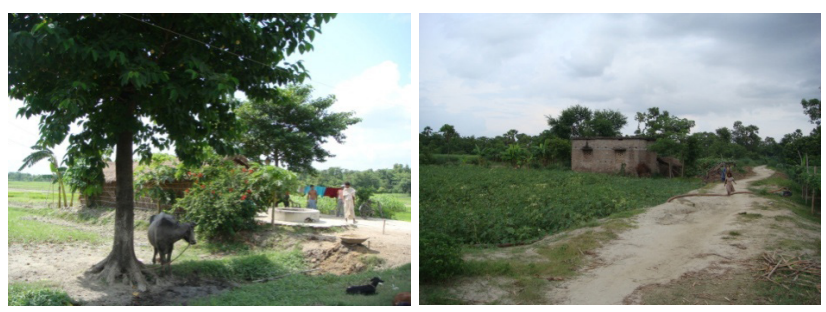

Figure 7\&8.Location of houses of cases

\section{Environmental Observations}

- The team visited various litchi gardens in the main affected blocks of Muzaffarpur district. It was observed that there was practice of plucking litchis very early in the morning upon enquiry it was communicated that if litchis are plucked during day when temperature is high its shell/ rind get darkened, which fetches lower prices.

- In order to pluck litchi early in the morning, to ensure that it does not get darkened, many of the families temporarily stay in litchi gardens only, where they cook food.

- Cooking food could attract wild rats and so people, especially children, may come in contact with rats and their droppings etc. This continues during plucking season of the litchi and ends once plucking is over which coincides with arrival of monsoon.

- It was observed that during the period of outbreak there were no crops in the farmlands where children from nearby house can come and play.

- Rat burrows were found in all the litchi gardens, farmlands and vacant land around the houses.

\section{Laboratory Result}

All the samples were negative for known causes of acute encephalitis like JE, Nipah and Chandipura viruses.

Zoonosis Division, NCDC, Delhi, got the samples of pig, mosquito and human, tested at National Research Centre Equines, Hissar with following results Pigs serum sample (3) - Negative for JE and West Nile (WN), Human Samples (3) - Negative for JE and WN \& Pooled Mosquito samples - Negative for JE and WNupto $2^{\text {nd }}$ Passage.

In addition, 17 serum samples of cases and contacts were processed at NCDC lab. Serum samples of one case and two contacts were found to be positive for Anti Parvo virus IgM and IgG antibodies.

\section{Entomological Report}

Mosquito collected were examined in the laboratory. All mosquito collected were found to be of species Armigeres.

\section{Discussion}

In a review article published after the review of populationbased studies which focussed on outbreak investigations and surveillance of AES, it was stated that for decades, 
JE has been considered to be the leading cause of AES in Asia with over 50,000 cases and 10,000 deaths reported each year. The history of AES in India has paralleled that of JE, with the virus first being reported from southern India (Vellore, Tamil Nadu) in 1955. Various subsequent studies confirmed that most AES in India are due to JE, which has been considered as the only major cause of $A E S$ in India. A high endemic burden of JE, together with frequent explosive epidemics, has led to adoption of mass vaccination strategies in endemic regions in India using alive-attenuated vaccine shown to provide more than $90 \%$ protection. However, several recent studies have reported that novel viruses such as Enteroviruses (ENV), Chandipura Virus (CHPV) and Nipah Virus (NV) may account for AES in theregions endemic for JE. This change may reflect either a true epidemiological effect or the use of improved diagnostic tests for non-JEV aetiologies. ${ }^{2}$

The review article further stated that the emergence of non-JEV aetiologies in outbreaks and surveillance studies directly impacts preventive measures for AES. While vector control programmes and JEV vaccination remain important strategies, the presence of other agents calls for designing and implementing novel preventive strategies that would focus on containment of water-borne enteroviruses and vectors for Chandipura virus. This will need a multisector approach involving health, water resources, sanitation and rural development departments. Recently the thought process on such an approach has been initiated. In addition, we also need to move from JE surveillance to surveillance for the entire spectrum of AES, so that evidence based public health actions can be planned and carried out. ${ }^{2}$

Similar findings were published in another study ${ }^{1}$ which states that in 2014 many cases of AES were reported from various States of India such as Uttar Pradesh (3,329 cases, 627 deaths), Assam (2,194 cases, 360 deaths), West Bengal (2,381 cases, 169 deaths), and Bihar (1,385 cases, 355 deaths) wherein JE was the major cause of these deaths, albeit virologists identified another causal agent in the form of 'toxin-mediated illness'. Investigators hypothesized the causal agent as a toxin prevalent in the litchi fruit. In these cases, although encephalitis was not confirmed, pathogenesis leads to encephalopathy with hypoglycaemia. Sixty-three percent of 390 patients suffered from hypoglycaemia with low blood glucose level of $70 \mathrm{mg} / \mathrm{dl}$, and it was observed that only treatment for hypoglycaemia reduced the number of deaths from $44 \%$ in 2013 to $26 \%$ in 2014 . The toxin was identified as methylene cyclopropyl glycine and was found to rise in litchi seed. Later, though not confirmed, the rise in the toxin in litchi seeds was implied to the use of alpha cypermethrin above the minimum safety levels.

In another hospital-based surveillance and nested age-matched case-control study, ${ }^{3}$ wherein laboratory investigations to assess potential infectious and noninfectious causes of this acute neurological illness was done it was concluded that this recurring outbreak of acute encephalopathy is associated with both hypoglycin A and MCPG toxicity from litchi consumption. This illness is also associated with absence of an evening meal. To prevent illness and save lives in Muzaffarpur, it was recommended to minimise litchi consumption among young children, ensuring children in the area receive an evening meal throughout the outbreak season, and implementing rapid glucose correction for children with suspected illness.

In another study ${ }^{4}$ published in 2014 it was stated that Dengue along with Chikungunya is emerging as an important cause of AES in India. Several other viruses including Herpes Simplex (HSV), Varicella Zoster (VZV), Cytomegalovirus (CMV), Human Herpes Virus-6 (HHV-6), Epstein Barr, JC, Measles, Mumps, Rubella, and Rabies have been reported to cause AES in India, most often as sporadic cases. Several non- viral pathogens can lead to a clinical presentation compatible with AES. They include Plasmodium falciparum (cerebral malaria), leptospira, bacteria causing meningitis like Streptococcus pneumoniae, Neisseria meningitides and Haemophilus influenzae, and Mycobacterium tuberculosis. However, same study says that the cause for a seasonal AES outbreak that occurs in Muzaffarpur, Bihar for several years has remained undetermined; hence it continues to be called a mystery disease.

In another review ${ }^{5}$ which summarizes the current JE/ acute encephalitis surveillance system in Asia and West Pacific region, with a specific focus on India. It was stated that in India, the etiological pathogens identified for acute febrile encephalopathy in a sizeable proportion of cases are of bacterial origin, and among viral pathogens JE virus, Enteroviruses, and Chandipura virus have been identified frequently in both outbreaks and hospital surveillance studies. Measles, Varicella Zoster, Mumps, and Herpes Simplex viruses also form a moderate proportion of sporadic cases presenting at hospitals. The pathogens differ by the geographic location of the study.

The soil type of outbreak areas in the districts which were mainly along the river bed was sandy and loose which is suitable for litchi growth and wild rats to make burrows. In addition it was found that during the period of outbreak there were no crops in the farmlands and it was reported that in the vacant farmlands children from nearby houses comes and play and gets exposed to the wild rats. This is very clearly seen on analysis of data collected from cases as majority of the houses (84.6\%), were surrounded by either farmland or litchi garden or any other type of agriculture land. The key observation which strengthen this was the sudden drop in incidence of cases with rainfall (ref figure 
3 ), as during and just after the rain children abandon the outdoor games in farmlands/litchi gardens due to accumulation of water in these areas and prevention of exposure from the rodents.

\section{Conclusions}

Clinico-epidemiological and environmental evidence supports the diagnosis of Acute Encephalitis Syndrome which has significant mortality, affecting predominantly rural population with poor sanitation. However it is unlikely to be Japanese Encephalitis, West Nile, cerebral malaria, NIPAH virus or Chandipura virus.

Evidences suggest that there were increased chances of contacts between cases and wild rats during the period of occurrence of outbreak. Etiological agent could not be identified by laboratory tests.

\section{Recommendation}

Detailed study on behavior and presence of parasites and zoonotic disease among wild rodents need to be conducted before next season in the affected area.

\section{Acknowledgement}

The authors acknowledge the efforts \& support provided by all members of investigation team i.e., Dr. Harish Chellani, Consultant Pediatrician, Safdarjung Hospital, Dr. (Mrs.) S. Aneja, Director Professor, LHMC, Dr. U.V.S Rana, Joint Director, NCDC and Dr. V. N. Shelke, NIV, Pune, Muzaffarpur, Bihar, in successful completion of investigation.

\section{Conflict of Interest: None}

\section{References}

1. Ghosh S, Basu A. Acute Encephalitis Syndrome in India: The Changing Scenario. Ann Neurosci 2016; 23:131-133. DOI: 10.1159/000449177. [Google Scholar].

2. Joshi R, Kalantri SP, Reingold A et al. Changing landscape of acute encephalitis syndrome in India: a systematic review. Natl Med J India 2012; 25: 212-220. [Google Scholar/ PebMed].

3. Shrivastava A, Kumar A, Thomas J D et al. Association of acute toxic encephalopathy with litchi consumption in an outbreak in Muzaffarpur, India, 2014: a case-control study. Lancet Glob Health 2017; 5: e458-466. [Google Scholar/ PebMed].

4. Ravi V, Mani R, Govekar S et al. Aetiology and Laboratory Diagnosis of Acute Encephalitis Syndrome with Special Reference to India. J Commun Dis 2014; 46(1): 12-23. [Google Scholar].

5. Shrivastava A. Acute Encephalitis Syndrome Surveillance: Challenges and the Way Forward. J Commun Dis 2014; 46(1): 73-85. Available from: https:// www.researchgate.net/publication/267267069_Acute_ Encephalitis_Syndrome_Surveillance_Challenges_and_ the_Way_Forward. [Google Scholar]. 